\title{
Impact of Staging the Procedure on Audiological Results in Canalwalldown Surgery for Cholesteatoma
}

\author{
Dr.Ravishankar .C. Dr.Sushma Nayak \\ Department of ENT, Bangalore medical college and Research institute Bangalore
}

\begin{abstract}
Cholesteatoma is a progressive destructive ear disease. Can affect any age group. But more severe in children and young adults. It erodes the bone of middle ear, mastoid and ossicles. It causes partial to total deafness, unpleasant smelling discharge, pain, tinnitus, vertigo and facial paralysis. It can even cause meningitis, brain abscess and death.

Canal wall down surgery is $95 \%$ effective in removing the disease and prevents recurrence of cholesteatoma. When the disease can be completely cleared to the satisfaction of the surgeon, reconstruction can be undertaken in the same sitting. When this cannot be done, reconstruction should be postponed to a later date. Staging of tympanoplasty gives a chance to relook and clear residual disease. There is lack of data on audiological outcome caused by such staging of reconstruction. So we would like to undertake the study to know the specific role of staging in improving audiological outcome.
\end{abstract}

\section{INTRODUCTION}

Attico-Antral disease, in particular, destroys the ossicles and has the potential to cause life threatening complications due to bone erosion nature of cholesteatoma. Surgical treatment of middle ear cholesteatoma remains one of the most challenging surgeries in otology. ${ }^{1}$

The primary objective of surgery for cholesteatoma is to eradicate the disease and rendering the ear safe and dry and second objective is to restore hearing to serviceable level by Tympanoplasty ${ }^{1}$.

Tympanomastoidectomy can be combined with ossicular reconstruction as a single stage when suspiscion of residual cholesteatoma is minimal.Factors like extensive mucosal disease of middle ear, lack of certainity of removing cholesteatoma dictates staged procedure. ${ }^{2}$

Staged procedure is done 6-9 months following primary clearance. It enables removal of residual and recurrence of cholesteatoma and reconstruction of hearing system. Staging is indicated in 70-75\% of ears with cholesteatoma. ${ }^{2}$ Hearing improvement varies depending upon several factors like the stage of the disease, degree of destruction of ossicles, state of middle ear mucosa, Eustachian tube function, the degree of pre-operative hearing loss and the material used for reconstruction ${ }^{4}$. Autologous ossicles and septal,conchal and tragal cartilages have become the workhorse of tympanoplasty. They are easily available, low cost and biocompatible. TORP and PORP are not only expensive but also have high rates of extrusion ${ }^{7}$.

\section{AIMS AND OBJECTIVES}

1. To know the impact of staging the procedure on audiological results in canal wall down surgery for cholesteatoma

2. To determine factors which demand staging of canal wall down surgery.

3. To determine is there any difference in audiological outcome between different materials used for reconstruction (cartilage \& TORP).

\section{Materials And Methods}

This is a prospective study conducted between December 2011 to January 2013 on 30 patients, who are willing to undergo surgery.

The patients were categorized into two groups. Those in group A had 15 patients who underwent canal wall down surgery with concurrent reconstruction of middle ear with temporalis facia graft and autograft or homograft incus,homogrft septal cartilage or TORP. The group B had 15 patients with previous canal wall down surgery without reconstruction, reconstruction of middle ear was done as a staged procedure.

The cartilage used was taken from the thick septal spur of other patients who had undergone septoplasty. The removed cartilage had been stored in $70 \%$ alcohol and was used whenever required.

The study was carried out at Sri Venkateshwara ENT institute and Bowring and Lady curzon hospital attached to Bangalore medical college and Research Institute, Bangalore. The data collected was analysed using Student " $t$ " test. 


\section{INCLUSION CRITERIA:}

All patients with confirmed preoperative cholesteatoma and who had undergone previous surgery after confirmation for fitness to undergo surgery and written informed consent.

\section{EXCLUSION CRITERIA:}

1. Sensorineural deafness .

2. Exposure to ototoxic drugs.

3. Intracranial complications due to cholesteatoma.

\section{Observations And Results}

Our study included 30 patients in the age group of 11-50 years, 13 were male and 17 were female, divided into two groups.

\section{Age and sex distribution:}

The age of patients in this study varied between 11 and 50 years. The mean age in the Group A was 25 years and in the Group B it was 29.3 years. In Group A 5(34\%) were male and remaining 10(66\%) were female patients. Group B too had 8(53.3\%) males and 7(46.6\%) females.

\begin{tabular}{|l|l|l|l|l|l|l|}
\hline $\begin{array}{c}\text { Age } \\
\text { Group }\end{array}$ & \multicolumn{1}{|c|}{ Group -A } & Total & Group -B & Total \\
\hline & Male & Female & & Male & Female \\
\hline $11-20$ & 1 & 5 & 6 & 3 & 2 & 2 \\
\hline $21-30$ & 2 & 2 & 4 & 2 & 2 & \\
\hline $31-40$ & 2 & 2 & 4 & 1 & 2 & 3 \\
\hline $41-50$ & 0 & 1 & 1 & 2 & 1 & 3 \\
\hline Total & $5(34 \%)$ & $10(66 \%)$ & 15 & $8(53.3 \%)$ & $7(46.6 \%)$ & 15 \\
\hline
\end{tabular}

\section{Table1. Age and sex distribution}

Symptoms:

Ear discharge and hard of hearing were the most common complaints, present in majority of the patients in both the groups.

\section{Side of presentation:}

Group A had 3 bilateral, 3 right sided and 9 left sided disease. Group B had 8 right sided disease, 7 left sided disease and no bilateral disease.

\section{Clinical Examination:}

Initially all the patients underwent clinical and microscopic examination in the our patient department. In Group A, all had cholesteatoma, along with cholesteatoma (3) $20 \%$ had granulations, (2) $13.33 \%$ had aural polyp, (2) $13.3 \%$ had attic perforation, (1) $6.67 \%$ had retraction pocket and in Group B, the majority $66.66 \%$ had dry cavity, $33.33 \%$ had discharging cavity, (1)6.67\% had granulations (1) $6.67 \%$ had cholesteatoma within the cavity.

\section{Pre operative investigations:}

Aural swab was taken and sent for culture and sensitivity tests. Pure tone audiometric evaluation was done for all the patients in a sound proof room with GSI 68 diagnostic audiometer following the standard procedure by the same audiologist. Pre and post operative audiometric testing was performed at 500, 1000, 2000 and $4000 \mathrm{~Hz}$.

\section{Follow up:}

The patients in both the groups were followed up every month. Post-operative audiometry was performed at the end of two, fourth and sixth months. There was no evidence of residual disease at the time of post-operative audiometry. On further follow up three patients showed discharging cavities. This responded well to daily aural toileting and antibiotics.

\section{Results:}

In Group A the mean pre and post operative Pure tone average results was $56.90 \mathrm{~dB}$ and $36.20 \mathrm{~dB}$ respectively. In Group B pre-operative Pure tone average results was $53.32 \mathrm{~dB}$ which improved to $38.31 \mathrm{~dB}$ post operatively. The results are depicted in table 6. 


\begin{tabular}{|c|c|c|}
\hline & $\begin{array}{c}\text { Pre } \\
\text { operative }\end{array}$ & $\begin{array}{c}\text { Post } \\
\text { operative }\end{array}$ \\
\hline Group A & 56.90 & 36.20 \\
\hline Group B & 53.32 & 38.31 \\
\hline
\end{tabular}

Table 2. Comparative results of mean Pre \& post-operative Pure tone average results of group A \& B

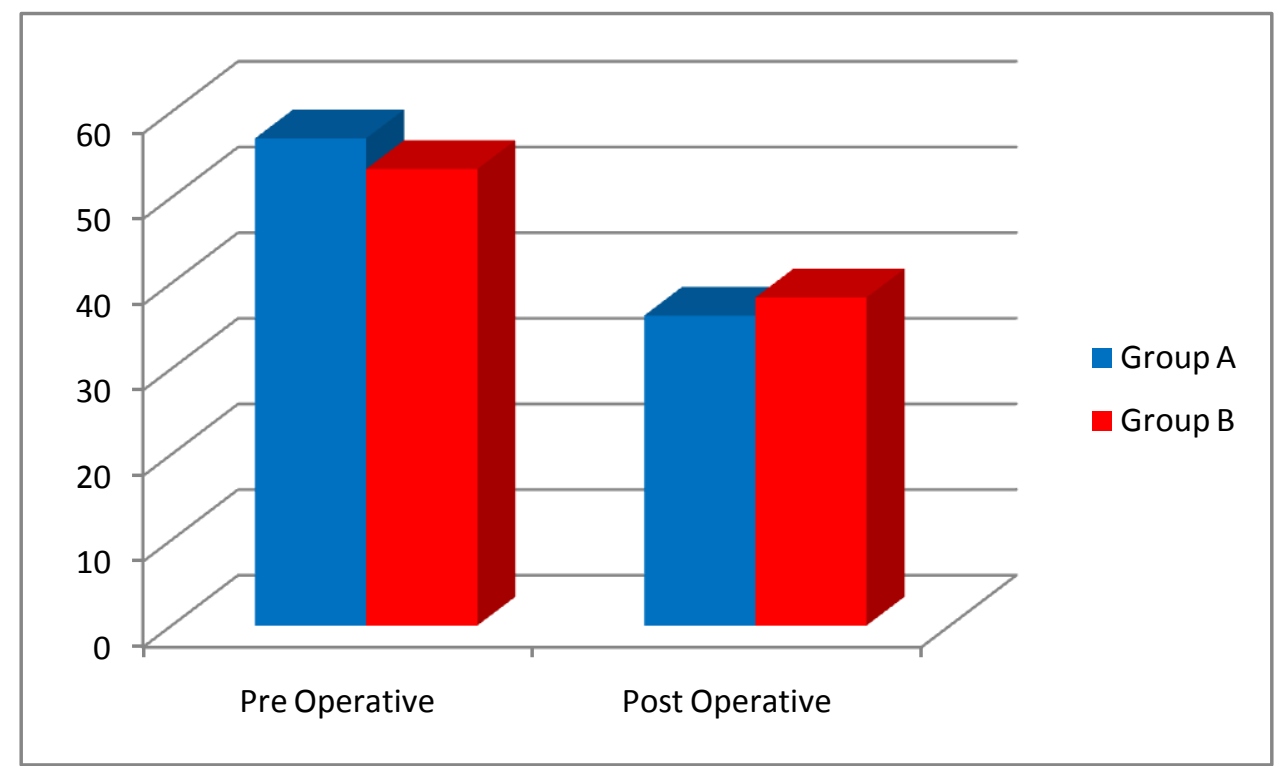

Chart 2: Comparative Mean Pure tone average results.

The hearing gain was compared and analysed using Student " $\mathrm{t}$ " test and the mean hearing gain in Group A was found to be $20.70 \mathrm{~dB}$ and that of Group B was found to be $15.01 \mathrm{~dB}$. P=0.041

\section{Discussion}

The cholesteatoma is a disease which is having propensity to involve various hidden areas in temporal bone, which leads to incomplete removal and recurrence of the disease. Lack of certainity of complete removal and extensively diseased mucosa were the reasons for staging in our study. Similarly presence of compramised mucosa was the reason for staging in study done by Berenholz et $\mathrm{al}^{3}$.

The hearing outcome was same in concurrent and staged ossiculr reconstruction in the study done by us. Similar audiological results were observed in studies done by Harold $\mathrm{H}$ et al. ${ }^{4}$, Sasaki et al. ${ }^{6}$ and Berenholz et $\mathrm{al}^{3}$. The successful outcome is defined as improvement of $15 \mathrm{~dB}$. In our study mean hearing improvement was $20.7 \mathrm{~dB}$ in patients who underwent concurrent reconstruction and $15.01 \mathrm{~dB}$ in patients who underwent staged reconstruction.

Table 3: Hearing results using different materials

\begin{tabular}{|c|c|c|c|c|c|}
\hline Authors & Material used & $\mathbf{n}$ & $\begin{array}{l}\text { Excellent } \\
(<10 \mathrm{~dB})\end{array}$ & $\begin{array}{c}\text { Good } \\
(11-20 \mathrm{~dB})\end{array}$ & $\begin{array}{c}\text { Fair } \\
(21-30 \mathrm{~dB})\end{array}$ \\
\hline Berenholz et. al. & PORP(Silastic) & 33 & $7(21.2 \%)$ & $9(27.2 \%)$ & $5(15.1 \%)$ \\
\hline Kadambari et.al. & Hydroxyl apatite & 20 & $2(10 \%)$ & $9(45 \%)$ & $6(30 \%)$ \\
\hline R A Chole & Cartilage & 102 & $26(25.5 \%)$ & $40(39.2 \%)$ & $24(23.5 \%)$ \\
\hline Robert C O'Reilly & Autograft Incus & 137 & $35(25.5 \%)$ & $56(40.9 \%)$ & $23(16.8 \%)$ \\
\hline
\end{tabular}

The Table No.3 showing the comparison of success rate in various studies using autograft ossicle or homograft cartilage with that of other prosthesis revealed more or less the same results as with synthetic prosthesis. In our study most of the reconstruction was done with septal spur cartilage, only in 2 patients TORP was used. Results were almost similar in view of hearing gain and reconstruction with septal cartilage is cost effective and efficacious. However, since in only two cases TORP was used, the comparison cannot be generalized. Hence there is a necessity to do randomized controlled study to validate the efficacy of TORP in comparison with autologous or homologus grafts. 


\section{Conclusion}

Although audiological results are same for both concurrent and staged reconstruction following canal wall down tympanomastoidectomy, concurrent reconstruction is preferred in limited disease, while staged reconstruction in severe disease.

Extensively diseased mucosa of middle ear and lack of certainity of complete removal of cholesteatoma are the factors which demand staging.

Autologus or homologus incus or homologus septal cartilage and TORP are equally effective in improving hearing outcome. TORP is more expensive compared to others.

\section{Bibliography}

[1]. George Browning, Scott.Brown's Otorhinolaryngology-Head and Neck Surgery,Vol.3.7 ${ }^{\text {th }}$ ed. Hodder Arnold,2008,CH.237C. Pg No.3407.

[2]. The otolaryngology clinics of North America Vol(22) No.5.1989.

[3]. Berenholz LP, Rizer FM, Burkey JM, Schuring AG, Lippy WH. Ossiculoplasty in canal wall down mastoidectomy. Otolaryngol Head Neck Surg 2000; 123: 30-33.

[4]. Kim HH, Battista RA, Kumar A, Wiet RJ.Should Ossicular Reconstruction Be Staged Following Tympanomastoidectomy. Laryngoscope 2006; 116: 47-51.

[5]. Shelton C, Sheehy JL. Tympanoplasty:review of 400 Staged cases.Laryngoscope 1990 Jul; 100(7):679-81.

[6]. Sasakit.T.et all. Results of hearing tests after Total middle ear reconstruction Acta otorhinology 2007 May 127(5):474-9

[7]. Ikeda M, Yoshida S, Ikui A, Shigihara S. Canal wall down tympanoplasty with canal reconstruction for middle ear cholesteatoma: postoperative hearing, cholesteatoma recurrence, and status of re-aeration of reconstructed middle ear cavity. J Laryngol Otol 2003; 117(4): 249-255. 